\title{
SOBRE EL RITUAL, LA VIOLENCIA, LA IDENTIDAD Y EL AGUANTE ENTRE LOS HINCHAS DEL FÚTBOL: ESTADO ACTUAL DE LA INVESTIGACIÓN SOCIAL ${ }^{1}$
}

\section{On the ritual, violence, identity and "el aguante" among supporters of football: Actual state of Social research}

\section{John Alexander Castro Lozano}

Candidato a Doctor en Estudios Sociales en la Universidad Distrital Francisco José de Caldas.

Correo-e: jacastrol@correo.udistrital.edu.co, ORCID: 0000-0001-8397-7690

Recibido: 25/5/2020 • Aprobado: 27/7/2020

Cómo citar: Castro Lozano, J. A. (2020). Sobre el ritual, la violencia, la identidad y el aguante entre los hinchas del fútbol: estado actual de la investigación social. Ciencia y Sociedad, 45(3), 65-83. Doi: https://doi.org/10.22206/cys.2020.v45i3.pp65-83

\section{Resumen}

Los grupos organizados de hinchas fueron visibilizados a partir de múltiples incidentes en Europa y en Iberoamérica, sucesos que se extendieron a partir de la década de 1960. En este sentido, se convirtieron en un problema de orden público para autoridades oficiales y deportivas y, además, medios de información. Igualmente, se constituyeron en un problema de investigación para antropólogos, psicólogos y sociólogos. Así, el propósito del artículo es detallar el estado actual de la investigación social relacionada con los grupos organizados de hinchas. De esta manera, las referencias fueron localizadas en bibliotecas electrónicas, investigaciones elaboradas desde distintos enfoques teóricos, conceptuales y metodológicos. Por último, la investigación social sobre los grupos organizados de hinchas se puede clasificar a partir de las nociones de violencia, identidad, ritual y un referente empírico, el aguante. Las categorías sociales y el referente empírico se han empleado para interpretar y comprender los comportamientos de los hinchas organizados grupalmente.

Palabras clave: rito; violencia; identidad; hinchas de fútbol; investigación interdisciplinaria.

\begin{abstract}
Organized Supporters Groups were made visible from multiple incidents in Europe and Ibero-America, events that spread from the 1960s. In this sense, they became a problem of public order for official and sports authorities and, in addition, the media. They also became a research problem for anthropologists, psychologists, and sociologists. Thus, the purpose of the article is to detail the current state of social research related to Organized Supporters Groups. In this way, the references were located in electronic libraries, investigations elaborated from different theoretical, conceptual and methodological approaches. Finally, social research on Organized Supporters Groups can be classified into the notions of violence, identity, ritual and an empirical reference, "el aguante". Social categories and the empirical referent have been used to interpret and understand the behavior of group-organized supporters.
\end{abstract}

Key words: rite; violence; identity; football supporters; interdisciplinary research.

$1 \mathrm{El}$ artículo es un avance de la tesis de grado intitulada ;Yo soy azul! La imitación y el aguante entre hinchas en Bogotá, desarrollada por el autor en la línea de investigación en Subjetividades, Diferencias y Narrativas en el Doctorado en Estudios Sociales de la Universidad Distrital Francisco José de Caldas. 


\section{Introducción}

Los grupos organizados de hinchas (GOH) fueron visibilizados a partir de múltiples incidentes en Europa e Iberoamérica, particularmente violentos; sucesos que se extendieron a partir de los años sesenta ${ }^{1}$. En Inglaterra emergió la violencia, en el contexto del fútbol, a través de actos vandálicos, originados antes, durante o después de los encuentros futbolísticos, disputados en el marco de la Copa Mundial de Fútbol (Dunning, Murphy, y Williams, 2016). En Argentina, la denominación de barras bravas se originó a partir del homicidio de Héctor Souto - seguidor de Racing Club de Avellaneda, en abril 9 de 1967-, el crimen fue cometido por hinchas de Club Atlético Huracán (Alabarces, 2012). Además, las barras bravas empezaron a obtener financiación por parte de los dirigentes de sus equipos (Romero, 1997). En Brasil, en la década de 1960, se constituyeron las torcidas organizadas, con una organización burocrática y participando en las decisiones del equipo (Palhares, Cabrera, y Schwartz, 2014).

Las tragedias sucedidas en el estadio de Valley Parade de Bradford (1985), en el Heysel de Bruselas (1985), y en el Hillsborough de Sheffield (1989) fue responsabilidad exclusiva —según autoridades oficiales y medios de información- de los hooligans. Algo semejante se afirmó con el desprendimiento de las barandas de seguridad de las graderías en el estadio Jornalista Mário Filho de Río de Janeiro (1992), en el Monumental de Santiago (1993) y en el Nemesio Camacho de Bogotá (1998) pues culparon a torcidas organizadas y barras bravas, respectivamente. No obstante, es necesario afirmar que estos incidentes ocurrieron por deficiencias estructurales, falta de control en la distribución de las entradas y la respuesta tardía de los organismos de emergencia. Los grupos organizados de hinchas se convirtieron en un problema de orden público por autoridades oficiales y deportivas y, además, medios de información. Asimismo, los GOH se constituyeron en un problema de investigación, especialmente para antropólogos, psicólogos y sociólogos, quienes identificaron a un actor, en un lugar específico, en un tiempo determinado y en situaciones particulares alrededor del fútbol.

De esta manera, la investigación social sobre los grupos organizados de hinchas inició a finales de 1960 en Inglaterra, los primeros estudios fueron Taylor (1971); Marsh, Rosser y Harré (1978); Popplewell (1985) y Dunning, Murphy y Williams (1988b). Posteriormente, la investigación social se ha incrementado — de forma gradual y significativa- hasta el año 2010 y se ha vinculado a la antropología, psicología o sociología del deporte o a los estudios sociales del deporte; investigaciones desarrolladas en distintos países, justamente en donde son un problema de orden público. Por ese motivo, el propósito del artículo es detallar el estado actual de la investigación social relacionada a los grupos organizados de hinchas, elaborada en Europa e Iberoamérica. La búsqueda sobre lo que se ha investigado es inevitable ya que "son expresiones de desarrollos investigativos, dados desde diversas percepciones de las ciencias sociales y escuelas de pensamiento, tarea emprendida y cuyo objetivo final es el conocimiento y la apropiación de la realidad social para luego disertarla y problematizarla." (Jiménez, 2004, p. 32).

El artículo se organiza de la siguiente manera: la introducción; los aspectos metodológicos; la manifestación de los rituales en los estadios; la preocupación por los incidentes violentos antes, durante o después de los encuentros futbolísticos; la constitución de la identidad entre los hinchas; la noción-experiencia del aguante; y, por último, algunas conclusiones.

\section{Aspectos metodológicos}

La búsqueda de las referencias fue realizada en bibliotecas electrónicas como la Red de Bibliotecas Virtuales del Consejo Latinoamericano de Ciencias Sociales (CLACSO); en el portal de acceso abierto 
-que visibiliza la producción científica de Hispanoamérica- Dialnet; en el catálogo de acceso público en internet de la Facultad Latinoamericana de Ciencias Sociales (FLACSO); en la Red de Revistas Científicas de América Latina y el Caribe, España y Portugal (RedALyC) y en Scientific Electronic Library Online (SciELO), una biblioteca electrónica que promueve la difusión y la visibilidad del conocimiento científico en Latinoamérica, el Caribe, España y Portugal. En la búsqueda inicial fueron empleadas y combinadas algunas palabras clave relacionadas a la temática de los hinchas organizados grupalmente como: hinchas, hinchada, hooligans, siders, ultras, torcidas organizadas y barras bravas. Los resultados de la búsqueda permiten indicar que la producción investigativa es diversa, pues los investigadores se ubican en distintas posiciones.

En otras palabras, el acercamiento - por parte de antropólogos, psicólogos y sociólogos- se logró desde variadas perspectivas teóricas y metodológicas, posibilitando la diversidad en los estudios. De esta manera, en la búsqueda se destacaron ochenta y tres (83) referencias - entre libros, artículos en revistas científicas y ponencias en eventos académicospublicadas en Iberoamérica, entre 1982 y 2018. El primer artículo publicado en español fue El orden social en las tribunas de los estadios de fútbol británicos de Peter Marsch. Y en el 2018, fueron publicados Alentando y peleando se tiene "aguante": la construcción de la identidad en una barra brava de John Castro; Ferroviarios, negros y aguantadores: sentidos e identidades en los cantos de la hinchada del club Central Norte de Mariana Ibarra y Aguante y violencia en el mundo de las barras futboleras mexicanas. Reflexiones metodológicas y éticas sobre el caso del Ritual del Kaos de Sergio Varela. Así, la figura 1 expone el aumento de las publicaciones referenciadas —en español y portugués_- desde 1982 hasta 2018.

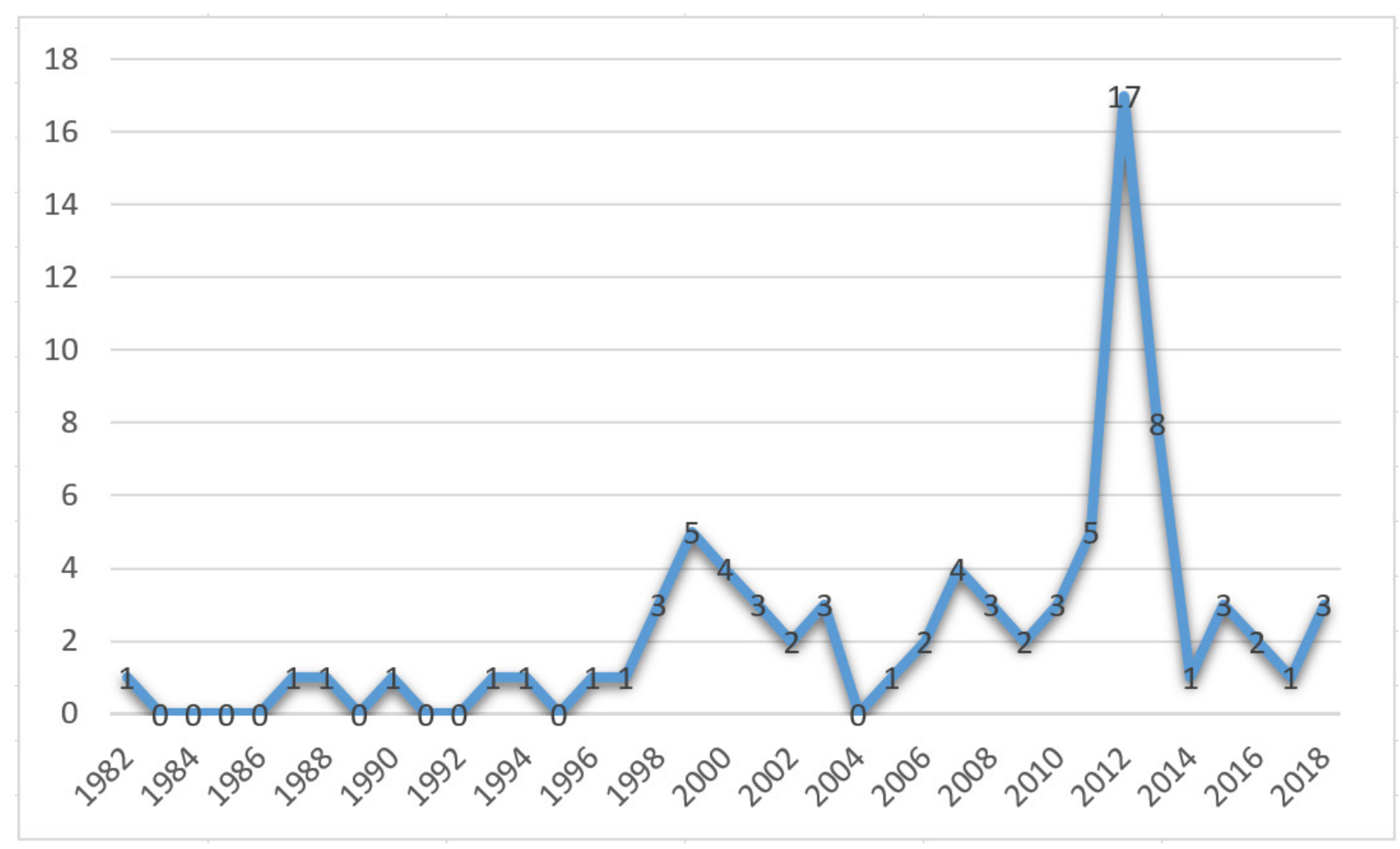

Figura 1. Referencias publicadas desde 1982 hasta 2018

Fuente: elaboración propia. 
La selección de las referencias se logró a partir de la identificación de palabras clave y la lectura intensiva, comprensiva y reflexiva de las publicaciones. El análisis documental y la elaboración de reseñas analíticas permitió, primero, la clasificación desde categorías comunes y, segundo, el registro de la hipótesis y la explicación sobre las manifestaciones de grupos organizados de hinchas. De manera que el artículo se organizó bajo las nociones de violencia, rituales, identidades y aguante, nociones comunes que permiten comprender e interpretar las regularidades entre los hinchas organizados grupalmente. El cuadro1 muestra las categorías de análisis, las referencias citadas a partir de cada una de las categorías y su distribución porcentual en el artículo:

Cuadro 1. Referencias citadas

\begin{tabular}{|c|c|c|}
\hline $\begin{array}{c}\text { Categorías de } \\
\text { análisis }\end{array}$ & $\begin{array}{c}\text { Referencias } \\
\text { citadas }\end{array}$ & Porcentaje \\
\hline Rituales & 12 & $14.46 \%$ \\
\hline Violencia & 18 & $21.69 \%$ \\
\hline Identidad & 31 & $37.35 \%$ \\
\hline Aguante & 22 & $26.51 \%$ \\
\hline & 83 & $100 \%$ \\
\hline
\end{tabular}

Fuente: elaboración propia.

Cada una de las categorías de análisis permiten comprender aspectos relacionados a los Grupos Organizados de Hinchas. La categoría de violencia posibilita descifrar las probables causas y los escenarios de las peleas entre los hinchas. La noción de identidad posibilita entender las rutinas, las experiencias y los estilos que exponen semejanzas, distinciones y especificidades entre los hinchas. El concepto de ritual permite observar la resignificación de los territorios y los emblemas y, también, destacar las expresiones festivas en torno a los partidos de fútbol. Y la noción-experiencia del aguante, es un referente empírico que permite comprender y explicar los comportamientos de las barras bravas y así, entender los rituales depor- tivos, las prácticas violentas o la construcción de la identidad. Sin embargo, las categorías señaladas no son multiabarcadoras, es decir, algunos aspectos relacionados a los Grupos Organizados de Hinchas no son entendidos en su totalidad por una sola categoría de análisis; mostrando la posibilidad de combinar las nociones presentadas e incluso, proponer otras.

\section{Estudios sobre la manifestación de los rituales en los estadios}

En esta sección se ubican las referencias que explican los actos y los comportamientos de los hinchas - caracterizados de hooligans, ultras, torcedores o barras bravas - como rituales contemporáneos expresados en los estadios. Por ritual se comprende una serie de acciones repetitivas y usuales que poseen un alto valor simbólico; se lleva a cabo por costumbre y muestra la simpatía o el afecto por una institución; tiene un escenario y un horario particular.

Prácticas rituales. Desde una metodología etnográfica, las reflexiones de Peter Marsch y Rom Harré posibilitan entender que el hooliganismo inglés se caracteriza por poseer un orden interno. De esta manera, la jerarquía entre los hooligans se organiza de la siguiente manera: novicios, alborotadores, animadores de coros, organizadores, cabezas locas y graduados. Las graderías de los estadios de fútbol permiten la manifestación ritualizada de acciones ofensivas, creando una ilusión de violencia y quizá, la expresión de sentimientos de fracaso en la vida cotidiana (Marsch, 1982). En este sentido, la jerarquía se compone desde un sistema de riesgos, carrera moral, que ponen a prueba a los integrantes porque si logran la victoria, lograrán un prestigio en el grupo, pero si pierden, serán seńalados y cuestionados. Los insultos y las amenazas en los partidos de fútbol son semejantes a un ritual, pues los intercambios verbales son más usuales que los enfrentamientos, intercambios que posibilitan una comunicación entre los hinchas y los jugadores y, de la misma manera, con los rivales (Harré, 1987). 
Los movimientos en masa, las coreografías, las canciones, los apodos y la vestimenta de los ultras españoles, expresados en los estadios de fútbol, exponen relaciones —internas y externas — entre los grupos sociales y las instituciones deportivas; ordenando la jerárquica, clasificada de la siguiente manera: vieja guardia o veteranos, duros o peleones y críos (Adán, 1993). El ingreso a los ultras italianos se establece a partir del parentesco con algún miembro y por el acatamiento a ciertas pruebas de paso, que lo pueden posibilitar una función entre los ultras. El ritual se manifiesta en el estadio con las banderas y los bombos, al ser parte de la elaboración de la coreografía (Signorelli, 1999). El guerreo - expresión utilizada por los hinchas que forman las barras bravas de Perú- produce una escala de valores, al destacar los comportamientos aceptados y las conductas rechazadas. También, es el principio que posibilita establecer la jerarquía de la barra de fútbol. El cara a cara es un encuentro con el otro (el rival) que, concluye en un enfrentamiento con los rivales históricos y es el resultado a los desafíos suscitados, logrando medir las fuerzas de los grupos encontrados (Castro R, 1999).

La ropa, la pintura y las banderas de los ultras españoles crean un escenario que tiene sus propias formas de actuación. Los hinchas ofenden e insultan a sus rivales por medio de coros y ademanes ofensivos, logrando la cohesión del grupo, tanto del propio como del oponente, siguiendo una metáfora o ritual de guerra que busca humillar al otro, pero no desaparecerlo. $\mathrm{Y}$ al interior del grupo se crea un orden vertical y cada nuevo miembro busca ascender y lo logra cuando es capaz de distinguirse de los demás (Bayona, 2000). La particularidad del fútbol está en la fuerte intervención corporal que llevan a cabo los espectadores para comunicar oral, gestual, musical o gráficamente el sacrificio por lo propio y el odio por el rival. La voz sirve para alentar o insultar, los gestos para expresar el entusiasmo o la desgracia, los instrumentos para exaltar o burlar y los mensajes para apoyar o despreciar (Bromberger, 2001).
Símbolos y rituales. Los hinchas colombianos exponen una actitud religiosa porque tienen un ideal divinizado de roles, expresiones que deben ser confirmadas en los partidos y son reguladas por el equipo, al promover la reunión de sus seguidores (Mateus y Mahecha, 2002). Los símbolos de los hinchas -en las torcidas organizadas - expresan peligro o muerte y son tomados del ambiente militar, musical o político, resaltando la fuerza, la determinación, el coraje, la astucia o la fidelidad. De este modo, los cantos exponen un combate de una forma ritualizada, afirmando la identidad del grupo y de los valores exaltados (Teixeira, 2006). Los hinchas costarricenses que integran las barras de fútbol tienen que seguir una serie de pruebas o de pasos para que los acepten y los reconozcan: asistir al estadio, portar la camiseta, participar en la salida del equipo, saltar, cantar, hacer una bandera y entender que, la rivalidad entre los hinchas sigue la Ley del Talión: ojo por ojo, diente por diente (Rodríguez O, 2007).

Cantos y rituales. Los cantos expresan su apoyo al equipo y están cargados de agresividad y de acciones violentas, contra otros hinchas en Colombia. De esta manera, los rituales son parte de un sistema de signos, manifestados en los comportamientos (Clavijo, 2010). Los cantos de cancha son un ritual de aliento de parte de los hinchas argentinos pues corean y felicitan a sus equipos o a sus jugadores, acompañados de las murgas. Asimismo, se burlan e insultan a los rivales y muestran la posibilidad del enfrentamiento, exaltando el uso del cuerpo (Bundio, 2016).

Por último, las investigaciones referenciadas en este apartado exponen la importancia de las camisetas, las banderas y las bufandas para los hinchas, ya que les permiten demostrar su afiliación futbolística. Asimismo, el alcance que logran las canciones, los saltos, los bombos y las banderas para demostrarle el apoyo a su equipo. De otra parte, entre los hinchas de distintos equipos — de tribuna a tribuna- se insultan y amenazan, es decir, un 
intercambio verbal, posibilitándoles la renovada significación de los espacios que ocupan y generar el escenario específico para los enfrentamientos. Y en lo referido a los grupos organizados de hinchas fue posible entender las formas de integración y cohesión, el ingreso de los aspirantes, su organización interna y el ascenso en la jerarquía. Sin embargo, este tipo de manifestaciones no son reconocidos como rituales por parte de los hinchas ya que la categoría de análisis es externa al grupo social.

\section{Investigaciones sobre los incidentes violentos}

En este apartado se hallan las referencias que analizan los hechos violentos entre los hinchas; sucesos que no son espontáneos ni accidentales ya que pueden ser planeados con anterioridad e incluso, es posible que sean el resultado de diferencias territoriales, económicas, políticas, religiosas o étnicas. De acuerdo con esto, la violencia de los $\mathrm{GOH}$ se ha convertido en una problemática de análisis de investigadores sociales, con el propósito de explicar sus (posibles) causas y los actores involucrados.

La teoría elisiana. A partir de los planteamientos de Norbert Elias (1939), distintos sociólogos han buscado explicar la problemática de la violencia del fútbol, protagonizada por los espectadores. De esta forma, en las comunidades de la clase obrera baja inglesa se tolera la agresividad como una forma de relación social porque encuentran sentido, posición y gratificación, al compartir nivel social, edad, sexo y unidad territorial (Dunning, Murphy, y Williams, 1988a). Asimismo, en el fútbol existe un porcentaje importante de integrantes de las clases populares españolas, quienes convierten el estadio en un escenario de guerra, buscando derrotar al adversario a través de ofensas y golpes y así, conservar el respeto (Cancio, 1990). Los principales protagonistas de la violencia del fútbol son jóvenes españoles, quienes encuentran una comunidad en la que pueden participar al sentirse reconocidos y desde las tribunas —ubicadas detrás de los arcosllevan a cabo sus actos agresivos (Durán, 1996). La violencia de los espectadores holandeses constituye identidades y rivalidades en los partidos de fútbol. Además, mediante la violencia les posibilita registrar quienes son parte del grupo y quienes no lo son. También, les permite superar el aburrimiento y el miedo a través de la experimentación del valor físico, las peleas (Spaaij, 2008).

Jóvenes y violencia. En las torcidas organizadas los hinchas no poseen una ideología política definida, las exigencias para ingresar son mínimas, son integradas, en su mayoría, por jóvenes, quienes pretenden que sus acciones sean exhibidas; la mediación y la interacción con los rivales es agresiva y violenta, mediante el uso del cuerpo ya que su propósito es amedrentarlos (Toledo, 1994). Las torcidas organizadas se constituyen en las ciudades y los jóvenes que las integran se sienten atraídos por la vestimenta, la fuerza y la cohesión del grupo. Además, las relaciones verticales, el estilo de vida y la violencia son uno de los principales códigos y símbolos sociales (Pimenta, 2000). La violencia emerge como una disputa simbólica y real por la identidad del grupo (y del equipo), que niega al otro al ser visto como un enemigo ya que es aficionado de un equipo adversario o diferente. Por ese motivo, quienes pretenden ser parte de las torcidas, están buscando un reconocimiento y una posición (Santos, 2003).

Sin embargo, en el contexto del fútbol coexisten distintas violencias, y esas violencias no pueden ser reducidas al comportamiento de las torcidas organizadas (Palhares y Schwartz, 2015). Los ultras italianos son integrados, en su mayoría, por jóvenes; agrupados por vínculos que se establecieron en el barrio, la escuela o por adhesión ideológica. Los ultras son altamente organizados a partir de una serie de acuerdos sobrentendidos. La violencia de los ultras, al interior del grupo, no es sancionable y 
está relacionada con la expresión de la masculinidad, la fuerza física, la agresividad y el desprecio por el adversario (Roversi, 1998). Los ultras españoles se identifican con particulares estilos de vida. Además, simulan la violencia mediante avalanchas, gritos, banderas o tambores, mostrando la fuerza del grupo y así, apoyando a su equipo (Rodríguez, 2003).

Las barras bravas son tribus urbanas conformadas, mayoritariamente, por jóvenes chilenos, quienes exhiben un tipo de entusiasmo o fervor en el estadio y la violencia se vincula a distintos agentes y múltiples factores alrededor del fútbol (Recasens, 2008). La participación de los jóvenes colombianos en las barras bravas está relacionada con la configuración cultural de la masculinidad, pues es una forma de obtener poder, influencia, posición y respeto en el grupo. Las peleas producen una memoria colectiva, que afianza la lealtad de los hinchas (Silva, 2010). Los hinchas jóvenes colombianos reflejan mayor arraigo por su equipo y demuestran mayor fidelidad, fervor y prácticas violentas. Asimismo, los hinchas que pertenecen a la barra adquieren prestigio y eligen estar allí guerreándola por el equipo (Morales y Morales, 2011).

Violencia y territorio. Las rivalidades del fútbol son históricas y generan sucesos violentos entre las barras bravas argentinas. Las rivalidades se originan en la apropiación y la pertenencia a un territorio, trasladadas al fútbol a través de las diferencias culturales (Romero, 1997). De esta manera, el espacio funciona como un territorio de expresión, pertenencia, representación y actuación, que les permite a los hinchas peruanos, encontrarse y pintarlo con sus respectivos símbolos. La identificación con el equipo de fútbol es fundamental y la relación con el otro (el rival) es mediante la violencia, manteniendo un estado de guerra entre ellos (Espinoza, 1999).

Las barras bravas peruanas - a través de recorridos y grafitis - apropian y dominan un territorio, impidiendo la presencia de grupos rivales. Sin embargo, pretenden irrumpir en los espacios de los rivales y obtener - por medio de robos- camisetas o banderas (Arboccó y O’Brien, 2013). Las barras bravas argentinas son grupos organizados, al ordenar su jerarquía y establecer relaciones de intercambio con distintos actores sociales (D'Angelo, 2012). Los hinchas ecuatorianos se apropian de las representaciones de su equipo y se enfrentan a otros hinchas en los bordes de los estadios. Los hinchas han tomado diferentes territorios y su alcance se observa a través de camisetas, caminatas, grafitis y el fútbol (Carrión, 2014).

Finalmente, en los estudios presentados en este apartado se observa una diversidad de perspectivas que permiten aproximarse a lo que - desde afuera del grupo social — se ha denominado como violencia. Aunque es necesario señalar que la violencia es un concepto versátil, ya que se manifiesta en diferentes lugares y participan múltiples actores: ejecutores, víctimas y testigos. Por ese motivo, la violencia puede ser comprendida de distintas maneras, al depender de la posición en la que se ubica el actor y, además, sus causas son múltiples. En este aspecto, los medios de información y las autoridades deportivas han señalado - como principales responsables- a los grupos organizados de hinchas de la violencia del fútbol, a partir de las múltiples peleas entre los aficionados. No obstante, los enfrentamientos - entre los hinchas que integran los grupos organizados de hinchas - no se entienden como violentos, pues son la demostración de formas de hombría y valentía; si es posible afirmarlo, es una manera de entender la masculinidad.

\section{Análisis sociales sobre la constitución de la iden- tidad entre los hinchas}

En esta sección se ubican las referencias que interpretan la constitución de la identidad a partir de la afiliación futbolística. En el contexto del fútbol es posible que múltiples situaciones exhiban identi- 
dades construidas a partir de, por ejemplo, la pertenencia, las emociones, las canciones o los jóvenes.

El territorio y la identidad. La identificación de un hincha con su club en Argentina, lo lleva a asemejarse a unos y a diferenciarse de otros. Esas distinciones pueden generar enfrentamientos entre ellos y es en el estadio de fútbol donde se puede exhibir la afiliación a un equipo, mostrando la pertenencia a un territorio, a través de las banderas (Ferreyra, 2001). La identidad tiene su fundamento en el antagonismo, el fútbol promueve una división del mundo en amigos y enemigos. El partido es el momento adecuado para el enfrentamiento y, además, es la ceremonia de la ilusión del enfrentamiento y el encuentro de un nosotros (Ferreiro, 2003). Asimismo, en el proceso de construcción de la identidad, los hinchas mexicanos en la barra, encierran un espacio determinado y luego lo ocupan. Durante el partido, extienden banderas para celebrar; se despojan su camiseta para festejar y responden, a las ofensas recibidas por parte de los hinchas rivales, con un lenguaje agresivo y rudo (Martínez y De la Barca, 2009).

La identidad se constituye desde la integración del hincha colombiano a la barra de fútbol y en la apropiación de sus territorios, identificando los límites y el uso del espacio público. La emoción es fundamental, pues le otorga un sentido a sus prácticas en la barra y al territorio (Salcedo y Rivera, 2007). De acuerdo con esto, en las barras bravas chilenas es posible la constitución de una nueva forma de identidad ya que los hinchas integran distintos aspectos de sus vidas al equipo y a la barra brava. Igualmente, la barra brava expone su identidad a través de las banderas y los bombos ya que exhiben los emblemas y los colores de su club (Parada, 2013). Los torcedores buscan su sentido de pertenencia y la construcción de una autoimagen positiva, reconocida por otros grupos como genuina a través del respeto y el temor. De esta manera, refuerzan sus redes de sociabilidad y les permite sentirse cohesionados (Santos, 2013).

La identidad y los cantos. Los cantos de las hinchadas argentinas combinan distintos géneros musicales y variadas problemáticas que no están relacionadas, precisamente al fútbol. Los cantos manifiestan expresiones sobre lo propio, el club y la hinchada. Asimismo, sobre lo contrario, el equipo rival y la hinchada rival. Además, los cantos de las hinchadas expresan amor, aliento, festejo, insulto, amenaza y violencia (Gándara, 1999). En este sentido, en los cantos de las hinchadas argentinas se constituye una identidad activa frente a una pasividad, es decir, un nosotros que se enfrenta a un otros, diferente y rival histórico, territorial y deportivo. Las temáticas de los cantos se relacionan a la identidad, la diferenciación, la violencia y el machismo, manifestados a través del aguante (Burgos y Brunet, 2000). Asimismo, los grafitis de los miembros de una barra brava colombiana expresan una subjetividad juvenil, resignifican el espacio urbano, constituyen su memoria colectiva, su identidad y delimitan, simbólicamente, su territorio (Mendoza, 2013).

La identidad y las rivalidades. Las rivalidades futbolísticas en Argentina se construyen históricamente, se concretan desde la identidad de los clubes y así, de los hinchas; manifestada mediante las representaciones contradictorias en lo social, lo económico, lo político y lo cultural; constituyentes de ciertos significados y valores (Levatti, 1998). Las prácticas sociales de los hinchas argentinos componen la identidad desde la experiencia cotidiana de los actores que se involucran en el fútbol. De esta manera, el territorio, lo futbolístico, lo pasional y lo económico elaboran las rivalidades del fútbol (Aragón, 2011). La identificación de un torcedor por un equipo, lo opone, inevitablemente a los torcedores de otros clubes. La rivalidad manifiesta algunos elementos de la estructura social que representan los equipos 
de fútbol (Louzada, 2011). De esta manera, si los hinchas en Colombia cantan, saltan, permanecen en la pelea y mantienen los puños en alto, les permite a los hinchas — quienes forman la barra brava— constituir la identidad desde esas prácticas. Asimismo, los aspectos relacionados a lo territorial, lo étnico o lo cultural manifiestan las rivalidades futbolísticas a través de los hinchas (Castro, 2015).

En México, los equipos tienen ciertas características vinculadas con el origen, la historia y el estilo de juego; particularidades asumidas por los hinchas para representarse a sí mismos. Los símbolos y las prácticas sirven para reforzar los vínculos de pertenencia y distinguirse de otros seguidores (Aceves, 2012). La rivalidad histórica y geográfica de los equipos es admitida por los miembros de las barras, constituyendo una identidad mediante la participación, la animación, el colorido y el folclor (Delgado y González, 2012). La relación entre la identidad del equipo, los aficionados, la ciudad y equipos e hinchas rivales y de ese modo, las diferencias entre las porras y barra son evidentes pues la barra expresa una forma particular de apoyar y ejercer la violencia (Zepeda, 2012). El equipo es una representación local y un símbolo de unidad entre los habitantes de una región, al vincular la identidad territorial y la identidad futbolística. Los aficionados son la manifestación del entusiasmo y el compromiso, rivalizando con equipos de otras regiones y con sus respectivos hinchas (Chong y Gavaldón, 2012).

Las rivalidades se pueden clasificar en endógenas (disputas entre hinchas del mismo equipo y con la policía) y en exógenas (disputas con hinchas de distintos equipos) (González, 2012). Los equipos poseen valores determinados y sus aficionados los aceptan; en torno a los equipos se organizan las barras con una jerarquía determinada y un sentido de pertenencia, que les permite promover el carnaval y ejercer la violencia (Rodelo y Armienta, 2012). La identidad, la representatividad y el orgullo de la población de un territorio son proyectadas en el equipo de fútbol y las rivalidades del fútbol son la expresión de distinciones históricas, étnicas, económicas, políticas y culturales (Macías, 2012). En las porras familiares y en las barras juveniles se adoptan y se adaptan valores masculinos, ordenándose jerárquicamente. Sin embargo, las prácticas y las relaciones en las porras familiares son horizontales (Varela, 2012).

En lo relacionado a los aficionados, ellos se reconocen como incondicionales con el equipo, expresándolo en su animación. Las rivalidades son un antagonismo en la competencia deportiva, expresión de las diferencias político-históricas, económico-sociales o culturales (Orellana, 2012). Las barras se constituyen a partir de compromisos y responsabilidades, prevalece la masculinidad y las rivalidades se manifiestan mediante la festividad y el aguante (Celestino, 2012). El fútbol es un pretexto y la barra es un medio que les posibilita a sus miembros realizar el carnaval, visibilizándolos en la ciudad ya que la barra es un grupo juvenil, sus integrantes socializan y apropian de un territorio (Cortés, Hinojosa, y García, 2012). Las identidades y las representaciones de la población de una región y de la afición se establecen desde un pasado cultural e histórico común (Cortés, Cruz, y Rueda, 2012). La configuración, la autoridad, la jerarquía, la ocupación de un territorio, los elementos comunicativos y la identificación-diferenciación son construidos los miembros de la barra, mediante los cantos, los saltos, las banderas y el aguante (Morales, 2012).

Los jóvenes y la identidad. Las barras bravas colombianas son un fenómeno social urbano que es constructor de procesos identitarios y sentidos de pertenencia en los jóvenes y muestra que, el aliento al equipo implica la exhibición de diferentes símbolos en un ambiente festivo en los estadios (Torres, 2012). Igualmente, las barras de fútbol, en Colombia, son integradas por jóvenes, quienes tienen particu- 
lares formas de comunicarse y de posicionarse en el contexto, poseen rituales y símbolos específicos que los distinguen de otros grupos sociales, constituyendo su identidad (Giraldo y Restrepo, 2017). Los hinchas logran desenvolver sus procesos de socialización en la barra brava y, además, la formación de una identidad colectiva (Miranda, Urrego, y Vera, 2015). Por último, los hinchas colombianos que forman las barras bravas, manifiestan dos violencias: simbólica y física; pues tienen como propósito agredir o eliminar al rival, estableciendo sus prácticas alrededor del aguante, una manera de confirmar su identidad (Gómez, 2011).

Por último, la afición futbolística permite acercar al semejante y distanciar al otro, aportando elementos significativos para definir a un yo-nosotros y un él-ellos, constituido a partir de las distinciones culturales, económicas, étnicas, futbolísticas, históricas, pasionales, políticas, sociales y territoriales; construyendo el amigo y el enemigo, es decir, quién se encuentra a favor y quién en contra. En otras palabras, la afición futbolística acerca a los hinchas del mismo club y, además, los cohesiona alrededor de los grupos organizados de hinchas. Sin embargo, la semejanza implica una diferencia pues los hinchas se distancian de los seguidores de otros equipos e integran distintos elementos que los separan aún más, generando las rivalidades en el contexto del fútbol, rivalidades que desembocan en insultos, amenazas y enfrentamientos. De esta manera, es posible señalar que, la construcción social de la identidad puede comprenderse como la afición futbolística entre los hinchas, especialmente aquellos que forman los grupos organizados de hinchas.

\section{Investigaciones empíricas: el aguante, el guerreo o el desmadre}

En este apartado se hallan las referencias que explican las manifestaciones y los comportamientos desde la perspectiva de los hinchas en las barras bravas. Las nociones-experiencias son el aguante, el guerreo y el desmadre. El aguante es una noción-experiencia originada entre las hinchas de Argentina. Luego, es adoptada y adaptada por distintos grupos organizados de hinchas de Hispanoamérica. El guerreo es una noción-experiencia de los hinchas que forman las barras bravas en Perú y el desmadre es una noción-experiencia de los hinchas que forman las porras de México. El aguante, el guerreo o el desmadre pueden entenderse - desde una posición externa a las hinchadas o a las barras bravascomo una forma de masculinidad e incluso, una masculinidad agresiva.

La violencia o el aguante. El aguante se expresa entre los integrantes de las hinchadas de fútbol argentinas como la manifestación de la valentía, la fuerza y la resistencia, constituyendo un cuerpo popular que deja a un lado el miedo. Además, es capaz de tolerar el dolor y puede responder agresivamente ante las adversidades, logrando su protección y su supervivencia. De esta manera, alcanza el respeto, pues se muestra fuerte y seguro de sí mismo, al asumir riesgos determinados o peligros inminentes (Elbaum, 1998). En Perú, las barras de fútbol manifiestan la obligación de defender el emblema y el territorio de la aparición de los hinchas rivales. Así, las peleas han dejado el estadio y se han reubicado en los barrios, recurriendo al grafiti como una señal de apropiación territorial. De otra parte, al interior de las barras, la jerarquía y la posición social se organiza y se mide a partir del enfrentamiento físico o el guerreo, contra los rivales y la policía (Panfichi, 1999).

El aguante surge como un complemento para el hincha ya que a través del dolor y la adversidad se manifiesta un goce en él y se puede mantener si es reiterado y el cuerpo muestra tolerancia. El aguante es una vivencia del "soporte del deseo o condensador de goce [,] se expresa una y otra vez en frases axiomáticas que sostienen el edificio de su sentido de ser y la ilusión de llegar a tener aquello que lo complete." (Oliveto, 2000). Además, a través de los grafitis y los cantos futboleros se relacionan ciertos 
aspectos sobre cuerpos masculinos. Los grafitis y los cantos futboleros en Argentina, expresan la adhesión a un club y, además, manifestaciones vinculadas a lo masculino, al representar una disputa simbólica de los verdaderos hombres, pues el aguante "es una forma de guapeza y se advierte más en desventaja: desafía a lo que se supone ganador." (Scharagrodsky, 2002, p. 183). De este modo, los hinchas ponen su cuerpo (buscando dejar a un lado la pasividad y la neutralidad) para defender lo propio; demostrando una masculinidad que implica soportar lo que venga, está basada en la ley del más malo y, además, le otorga prestigio a quién la demuestra y lo puede ubicar en una posición en la barra brava chilena. Esta masculinidad se denomina el aguante, una ideología que involucra distintas vivencias: amistad y aventura, lealtad a sus compañeros y odio por el enemigo, pasión por el club y sus emblemas (Abarca y Sepúlveda, 2005).

La violencia entre las hinchadas argentinas se identifica como la cultura del aguante y es aceptada de manera positiva porque legitiman sus prácticas y les sirve para interactuar con aquellos que son parte y no hacen parte de la hinchada pues les posibilita obtener intercambios de bienes, favores y servicios; logrando un compromiso moral de las partes involucradas. Por eso, se acepta el coraje y la bravura en el enfrentamiento y de esa manera, es un capital simbólico para detentar (Garriga, 2010) En este sentido, le permite, a quien lo demuestra, ubicarse en la parte más alta de la jerarquía de la hinchada pues es un sistema de prestigio, de honor y de diferenciación social. De esta manera, la identidad se constituye, a través del cuerpo, en las experiencias y en las prácticas violentas, reflejado, primero, en las cicatrices, resultado del enfrentamiento, y segundo, en el tatuaje, vínculo con el equipo y con el grupo (Zambaglione, 2011).

El aguante es una masculinidad agresiva - relacionada al honor- que puede exteriorizarse (individual y colectivamente) al frente del otro, mediante la violencia. El aguante se apoya en el relato para respaldarlo a través de las cicatrices en el cuerpo, testimonio de la participación en el combate. Por eso no se permite expresar el dolor, solamente los machos se la aguantan. Asimismo, la hinchada se ubica y se adueńa de un territorio: el estadio y el barrio (Alabarces, 2012). De este modo, la ropa deportiva de un club de fútbol (y el tatuaje) le permite al hincha exhibir su identificación futbolística y debe asumir las consecuencias de su demostración. En otras palabras, si es necesario debe pelear y mantenerse en el combate, es decir, debe enfrentarse con los rivales, defendiendo su honor (individual), junto a la grandeza de su hinchada y de su club; distinguiéndose, al lograr la aprobación de sus conductas violentas en la hinchada (Czesli, 2013).

El aguante demuestra un uso justificado y característico del cuerpo para el enfrentamiento con el otro, manifestando una manera específica de ser hombre, corriendo riesgos, demostrando el aguante. El aguante lo ubica en una posición favorecida en la jerarquía de la barra. De esta manera, el aguante posibilita alcanzar beneficios para aquellos que lo demuestran. No obstante, el aguante se ha trasformado, ya que los nuevos miembros no respetan a los otros hinchas y priorizan el consumo de drogas. (Dodaro, 2006). En otras palabras, el combate posibilita la pertenencia, alcanzando la reputación y estableciendo la jerarquía en la hinchada pues enfrentarse a otros establece la autoridad del aguante. En este aspecto, la hinchada argentina es liderada por los jefes o los capos, quienes reciben las entradas y el dinero para los partidos. Los jefes o los capos son respaldados por los hombres influyentes, delegados para cuidar las banderas, planificar los viajes y brindarle seguridad a los buses cuando van a estadios rivales (Moreira, 2009).

Las prácticas relacionadas a la violencia poseen distintos sentidos y valoraciones. Y en el contexto del fútbol, los hinchas violentos argentinos (usualmente denominados como barras bravas) usan su cuerpo para demostrar su aguante, una categoría 
práctico-moral. Posteriormente, podrán exhibir cicatrices y relatar lo ocurrido en el enfrentamiento, ya que el aguante les posibilita la distinción en la hinchada, al otorgarles honra y prestigio (Daskal, 2013). En este aspecto, el mando en la hinchada se establece desde la demostración y la posesión del aguante; la masculinidad, las prácticas y el cuerpo están relacionados. El hincha debe aguantar las distintas experiencias para ser identificado como hombre o macho; contrario a los putos, aquellos que no son verdaderos hombres pues evaden los compromisos y los hábitos, indicando que carecen del aguante (Cabrera, 2013). El aguante es demostrado por los hinchas argentinos que forman la barra brava del club y es a través de la violencia que tienen que hacerlo. Sin embargo, no todos los hinchas lo exponen, y tampoco es aprobado por ellos, especialmente por aquellos que no son parte de la barra brava (Hasicic, 2016).

El aguante es un capital simbólico que se caracteriza por la fidelidad de los hinchas argentinos, las prácticas violentas contra los rivales y el consumo de sustancias ilegales; un capital simbólico manifestado en la distribución de ciertos privilegios, en la apropiación de un territorio, en la resignificación de las derrotas deportivas y en el ejercicio de una forma de poder (Ibarra, 2018). Por último, el aguante es la práctica de una forma de masculinidad, manifestada como un código de honor y hermandad, que constituye un nosotros. Así, vincula emocionalmente a los integrantes de las barras en México desde el consumo de drogas y bebidas embriagantes hasta la participación y la solidaridad en los enfrentamientos. "Las acciones de 'violencia', físico-corporales o simbólico-discursivas [...] tienen una teleología, es decir una racionalidad encaminada a la consecución de fines ulteriores dentro y fuera de la barra." (Varela, 2018, p. 119).

La festividad y la violencia o el aguante. El aguante es posible entenderlo como un capital simbólico. De esta manera, el hincha colombiano (que integra la barra) debe demostrarlo, buscando integrarse al grupo y así, le permite sobrellevar las adversidades del equipo y de la barra misma, al ser la expresión de un tipo de masculinidad. Asimismo, la barra posibilita desarrollar formas carnavalescas y agresivas en los estadios y en la ciudad (Pardey, Galeano, y Blanco, 2001).

El aguante se constituye - desde el cuerpo, la agresividad, la valentía el compañerismo, el fervor, la pasión hasta la fidelidad- como un modelo masculino y es un sentimiento y un principio moral, que se vincula al apoyo (aliento) al club y a la capacidad para luchar contra los rivales, pues son odiados. La exhibición del aguante le posibilita a la hinchada en Argentina distinguirse como poseedora de la identidad del equipo y la apropiación del territorio es uno de sus fundamentos (Gil, 2007). El aguante entre los hinchas en Argentina se demuestra en dos sentidos: el primero, poner el cuerpo 'a lo que sea', a partir del aliento al equipo durante el encuentro futbolístico hasta 'plantarse de manos' para defender las pertenencias, por ejemplo, de las banderas, o atacar a los rivales para robar sus banderas. El segundo, un significado emocional, es decir, alentar al equipo sin importar sus resultados, sus dificultades administrativas o pierda algún símbolo de la institución (Aragón, 2007).

El desmadre describe las acciones de los jóvenes en México, particularmente en las porras. En este sentido, es una forma de comportarse y demostrar la emotividad, apoyando al equipo de fútbol, es decir, la manifestación del sentimiento por el club. Asimismo, el desmadre exhibe una forma de masculinidad —adoptando el papel de macho al frente de las mujeres-, que organiza la jerarquía interna de la porra (Magazine, 2008). De manera que, el aguante es dicotómico. Primero, es aguante-presencia o aguante fiesta ya que les posibilita a los hinchas aguantar los reveses deportivos, desde la festividad. Y segundo, el aguante-enfrentamiento se vincula a las adversidades y al dolor físico 
(Sodo, 2013). Por último, las expresiones festivas y las conductas violentas —entre los hinchas en Colombia que forman las barras bravas- demuestran el aguante; un estilo de vida que permite constituir una forma de identidad en el contexto del futbol y, además, los rituales del aguante establecen pertenencia, participación, distinción; aceptando las rivalidades (Castro, 2018).

Finalmente, las nociones-experiencias del aguante, el guerreo y el desmadre, —usados como referentes empíricos en múltiples investigaciones- permiten identificar dos tendencias en las investigaciones referenciadas. La primera lo entiende desde la perspectiva de la violencia, y la segunda, a partir de las expresiones festivas y las manifestaciones violentas. Si se parte de las referencias citadas, es posible comprender las múltiples formas de socialización entre los hinchas en las hinchadas o las barras bravas. De este modo, se sugiere desarrollar una investigación que entienda que, el carnaval y el combate no son contradictorios, por el contrario, son complementarios, pues los hinchas deben estar en las tribunas y en las calles. La participación en el carnaval y la permanencia en el combate demuestran el aguante entre los hinchas que forman las hinchadas o las barras bravas. Además, el aguante, el guerreo y el desmadre son nociones-experiencias que se expresan en un particular contexto social, al estarlo no son expresiones-vivencias estáticas, sino dinámicas, al transformarse según las situaciones y las nuevas generaciones de hinchas en el grupo social.

\section{Algunas conclusiones}

El propósito de este artículo fue detallar el estado actual de la investigación social relacionada a los grupos organizados de hinchas. Las referencias citadas permiten entender los comportamientos o las manifestaciones de los $\mathrm{GOH}$ antes, durante y después de los encuentros futbolísticos desde las categorías del ritual, la violencia y la identidad, e igualmente, desde la noción-experiencia del aguante, el guerreo o el desmadre. Sin embargo, toda selección implica una exclusión, ya que múltiples referencias no están incluidas; particularmente las investigaciones publicadas en alemán, francés, inglés, italiano, entre otros idiomas. De esta manera, es posible sugerir la construcción de una (nueva) revisión — desde otras y nuevas referencias sobre los hinchas organizados grupalmenteque permita ampliar la perspectiva de análisis y comprensión sobre esta temática, elaborando un nuevo balance.

De otra parte, las categorías de análisis de ritual, violencia e identidad son el enfoque etic porque posibilita entender a los $\mathrm{GOH}$ desde afuera. Los cantos, los saltos, los enfrentamientos, el uso de las camisetas, banderas y bufandas son acciones repetitivas que son manifestadas en los estadios, manifestaciones entendidas como rituales. Las conductas violentas son la exhibición de una forma de masculinidad, expresada a través de la valentía, la hombría, el orgullo o el honor. Igualmente, las explicaciones sobre la identidad contribuyen en la explicación de un yo-nosotros y un él-ellos, constituido desde el origen territorial y grupal, entre otros aspectos. Sin embargo, desde la posición de los hinchas que forman los $\mathrm{GOH}$, este tipo de acciones no son calificadas como rituales, violencias o identidades.

Y el aguante, el guerreo o el desmadre es la perspectiva emic pues permite comprenderlos desde adentro, es decir, desde sus experiencias y sus relatos, entender las manifestaciones festivas y los enfrentamientos entre los hinchas. Dicho de otra forma, el aguante, el guerreo o el desmadre posibilitan múltiples maneras de entender las experiencias de los hinchas que forman los $\mathrm{GOH}$, es decir, explicar los rituales, la violencia y la identidad. El aguante, el guerreo o el desmadre son nociones y experiencias vivenciadas por los hinchas que forman las barras bravas; nociones y experiencias que se caracterizan por ser conductas festivas y agresivas en el contexto del fútbol. Por último, el enfoque etic y la perspectiva 
emic son complementarios porque logran integrar la interpretación desde afuera y la comprensión desde adentro.

Así, es posible señalar que, los $\mathrm{GOH}$ son una temática de indagación o, por lo menos, de inquietud en la antropología, psicología o sociología del deporte o los estudios sociales del deporte. El interés -en este tema de investigación específico- se puede explicar a partir del surgimiento de campos de estudio interdisciplinares y emergentes, el declive de los relatos totalizantes, la variedad de metodologías y el interés por examinar y explicar a los sujetos que integran grupos sociales, en particulares situaciones y en determinados contextos en las sociedades contemporáneas. Finalmente, este artículo pretende continuar, desde otras y nuevas referencias, la comprensión de las conductas de los hinchas (sujetos) en las barras bravas (grupo social) en el contexto del fútbol (escenario particular) a partir de una variedad de investigaciones desarrolladas.

\section{Referencias}

Abarca, H., y Sepúlveda, M. (2005). Barras Bravas, pasión guerrera. Territorio, masculinidad y violencia en el fútbol chileno. En F. Ferrándiz, y C. Feixa, Jóvenes sin tregua. Culturas y politicas de la violencia (pp. 145-169). Barcelona: Anthropos Editorial.

Aceves, R. (2012). Aficionados futboleros en Guadalajara: características y representaciones de rojiblancos, rojinegros y tecolotes. En R. Magazine, S. Martínez, y S. Varela, Afición futbolistica y rivalidades en el México contemporáneo: una mirada nacional (pp. 89-114). México: Universidad Iberoamericana.

Adán, T. (1993). Nuevos escenarios, viejos rituales. Los "ultras" del fútbol. Revista de Antropología Social, (2), 149-166.

Alabarces, P. (2012). Crónicas del aguante: Fútbol violencia y politica. Buenos Aires: Capital Intelectual.
Aragón, S. (2007). "Los trapos se ganan en combate": Una mirada etnográfica sobre las representaciones y prácticas violentas de la "barra brava" de San Lorenzo de Almagro. Lanús: Antropofagia.

Aragón, S. (2011). La construcción de identidades $y$ rivalidades futbolisticas, en Buenos Aires. Recuperado el 9 de junio de 2016, de Esporte e Sociedade: http://www.uff.br/esportesociedade/pdf/es1702.pdf

Arboccó, M., y O’Brien, J. (2013). Barras bravas y tiempos bravos: Violencia en el fútbol peruano. Avances en psicología, 21(2), 155-166.

Bayona, B. (2000). Rituales de los ultras del fútbol. Politica y Sociedad, (34), 155-173.

Bromberger, C. (2001). Las multitudes deportivas: analogía entre rituales deportivos y religiosos. Recuperado el 12 de febrero de 2020, de Lecturas: Educación Física y Deportes: http:// www.efdeportes.com/efd29/ritual.htm

Bundio, J. (2016). Un análisis del contenido y la melodía de los cantos de cancha desde sus orígenes hasta las tendencias actuales. En A. Levoratti, y V. Moreira, Deporte, cultura y sociedad: estudios socio-antropológicos en Argentina (pp. 269-292). Buenos Aires: Editorial Teseo.

Burgos, R., y Brunet, M. (2000). Un análisis de los cantos de los hinchas de Gimnasia y Esgrima de Jujuy. Recuperado el 12 de febrero de 2020, de Lecturas: Educación Física y Deportes. Revista Digital: http://www.efdeportes.com/ efd26a/jujuy.htm

Cabrera, N. (2013). De corporalidades masculinas, aguantadoras y populares. Violencia, identidad y poder en la hinchada del Club Atlético Belgrano. En J. Garriga, Violencia en el fútbol: Investigaciones sociales y fracasos politicos (pp. 127-151). Buenos Aires: Ediciones Godot.

Cancio, M. (1990). Sociología de la violencia en el fútbol. Cuadernos de Ciencias Sociales, artísticas y de la naturaleza, (1), 1-41. 
Carrión, F. (2014). Violencia en el fútbol: razones de una sinrazón. En F. Carrión, y M. Rodríguez, Luchas urbanas alrededor del fútbol (pp. 195-210). Quito: Facultad Latinoamericana de Ciencias Sociales.

Castro, J. (2015). Identidad y rivalidad en una barra brava en Bogotá. Revista de Antropología y Sociologia: Virajes, 17(1), 207-228.

Castro, J. (2018). Alentando y peleando se tiene "aguante": la construcción de la identidad en una barra brava. En R. Jaramillo, G. Gómez, y J. Castro, Fútbol y barras bravas: análisis de un fenómeno urbano (pp. 323-462). Bogotá: Siglo del Hombre Editores / Universidad Nacional de Colombia.

Castro, R. (1999). Un día de partido. Comunidades sentimentales y rituales violentos en la Trinchera Norte. En A. Panfichi, y M. Valcárcel, Juventud: sociedad y cultura (pp. 173-222). Lima: Red para el Desarrollo de las Ciencias Sociales en el Perú.

Celestino, M. (2012). El clásico norteńo Monterrey vs. Tigres: una 'rivalidad' mediática. En R. Magazine, S. Martínez, y S. Varela, Afición futbolistica y rivalidades en el México contemporáneo: una mirada nacional (pp. 115-141). México: Universidad Iberoamericana.

Chong, B., y Gavaldón, E. (2012). "Por lógica... porque soy lagunero": los aficionados al Santos Laguna. En R. Magazine, S. Martínez, y S. Varela, Afición futbolistica y rivalidades en el México contemporáneo: una mirada nacional (pp. 247-268). México: Universidad Iberoamericana.

Clavijo, J. (2010). Cantar bajo la anaconda: un análisis sociocultural del barrismo en el fútbol. Bogotá: Editorial Pontificia Universidad Javeriana.

Cortés, E., Cruz, J., y Rueda, K. (2012). La afición de los Diablos Rojos del Toluca. En R. Magazine, S. Martínez, y S. Varela, Afición futbolistica y rivalidades en el México contemporáneo: una mirada nacional (pp. 269-283). México: Universidad Iberoamericana.
Cortés, E., Hinojosa, D., y García, A. (2012). La Banda del Rojo de los Diablos del Toluca. En R. Magazine, S. Martínez, y S. Varela, Afición futbolistica y rivalidades en el México contemporáneo: una mirada nacional (pp. 315-332). México: Universidad Iberoamericana.

Czesli, F. (2013). Apuntes sobre la identidad en la hinchada de Platense. En J. Garriga, Violencia en el fútbol: Investigaciones sociales y fracasos políticos (pp. 95-127). Buenos Aires: Ediciones Godot.

D'Angelo, N. (2012). Barrabravas en Argentina: concepciones tradicionales frente a un nuevo modelo de intervención violenta. Recuperado el 12 de febrero de 2020, de Lecturas: Educación Físisca y Deportes: http://www. efdeportes.com/efd168/barrabravas-en-argentina-intervencion-violenta.htm

Daskal, R. (2013). Cultura, civilización y violencia en el fútbol argentino. En J. Garriga, Violencia en el fútbol: Investigaciones sociales y fracasos políticos (pp. 69-93). Buenos Aires: Ediciones Godot.

Delgado, E., y González, J. (2012). De "Los de arriba" a "Los hijos de la mermelada": barrismo y música en El Bajío. En R. Magazine, S. Martínez, y S. Varela, Afición futbolistica y rivalidades en el México contemporáneo: una mirada nacional (pp. 153-174). México: Universidad Iberoamericana.

Dodaro, C. (2006). Aguantar no es puro chamuyo. Estudio de las transformaciones en el concepto nativo. En P. Alabarces, Hinchadas (pp. 105-125). Buenos Aires: Prometeo Libros.

Dunning, E., Murphy, P., y Williams, J. (1988a). "Informales", "pandillas de grada", y "compañia de pelea”: Hacia una explicación sociológica del vandalismo en el fútbol. En D. Riches, El fenómeno de la violencia (pp. 225-249). Madrid: Ediciones Pirámide.

Dunning, E., Murphy, P., y Williams, J. (1988b). The roots of football hooliganism: an historical and sociological study. London: Routledge y Kegan Paul. 
Dunning, E., Murphy, P., y Williams, J. (2016). La violencia en los espectadores de fútbol. Hacia una explicación sociológica. En N. Elias, y E. Dunning, Deporte y Ocio en el proceso de la civilización (pp. 321-348). Ciudad de México: Fondo de Cultura Económica.

Durán, J. (1996). El vandalismo en el fútbol. Una reflexión sobre la violencia en la sociedad moderna. Madrid: Gymnos Editorial.

Elbaum, J. (1998). Apuntes para el 'aguante'. La construcción simbólica del cuerpo popular. En P. Alabarces, R. Di Giano, y J. Frydenberg, Deporte y Sociedad (pp. 157-162). Buenos Aires: Editorial Universitaria de Buenos Aires.

Elias, N. (1939). Über den Prozeß der Zivilisation. Soziogenetische und psychogenetische Untersuchungen. Basilea: Verlag Haus zum Falken.

Espinoza, A. (1999). Mi barrio es zona crema: territorialidad y conflicto en un grupo barrial de la Trinchera Norte. En A. Panfichi, y M. Valcárcel, Juventud: sociedad y cultura (pp. 223-271). Lima: Red para el Desarrollo de las Ciencias Sociales en el Perú.

Ferreiro, J. (2003). 'Ni la muerte nos va a separar, desde el cielo te voy a alentar' Apuntes sobre identidad y fútbol en Jujuy. En P. Alabarces, Futbologias. Fútbol, identidad y violencia en América Latina. (pp. 57-69). Buenos Aires: Consejo Latinoamericano de Ciencias Sociales.

Ferreyra, A. (2001). Lugares, hombres y banderas de fútbol. Temas y problemas de comunicación, 11, 81-90.

Gándara, L. (1999). Las voces del fútbol. Análisis del discurso y cantos de cancha. Recuperado el 12 de febrero de 2020, de Lecturas: Educación Física y Deportes: http://www.efdeportes. com/efd17/leliag.htm

Garriga, J. (2010). Haciendo amigos a las piñas. Violencia y redes sociales de una hinchada de fútbol. Buenos Aires: Prometeo Libros.
Gil, G. (2007). Hinchas en tránsito: Violencia, memoria e identidad en una hinchada de un club del interior. Mar del Plata: Editorial de la Universidad de Mar del Plata.

Giraldo, N., y Restrepo, J. (2017). Construcción de identidad en jóvenes de Manizales vinculados a barras de fútbol. Ánfora, 24(42), 165-187.

Gómez, G. (2011). Las barras bravas. Un acercamiento sociológico a un fenómeno urbano. Lúdica pedagógica, 2(16), 56-61.

González, M. (2012). Rivalidades sociales y culturales en torno a un grupo de animación de un equipo de fútbol. El caso de la Ultra 1901 de Pachuca. En R. Magazine, S. Martínez, y S. Varela, Afición futbolistica y rivalidades en el México contemporáneo: una mirada nacional (pp. 287-313). México: Universidad Iberoamericana.

Harré, R. (1987). El gamberrismo en el fútbol. Revista de Occidente, (70), 55-78.

Hasicic, G. (2016). Hinchas e identidad. Alcances y limitaciones de la ética del aguante. Perspectivas de la Comunicación, 9(2), 131-155.

Ibarra, M. (2018). Ferroviarios, negros y aguantadores: sentidos e identidades en los cantos de la hinchada del club Central Norte. Revista del Cisen Tramas/Maepova, 6(1), 159-179.

Jiménez, A. (2004). El estado del arte en la investigación en las ciencias sociales. En A. Jiménez, y A. Torres, La práctica investigativa en ciencias sociales (pp. 27-42). Bogotá: Universidad Pedagógica Nacional.

Levatti, A. (1998). Colón-Unión: violencia y rivalidad. En P. Alabarces, R. Di Giano, y J. Fridenberg, Deporte y Sociedad (pp. 103-109). Buenos Aires: Editorial Universitaria de Buenos Aires.

Louzada, R. (2011). Identidade e Rivalidade entre os Torcedores de Futebol da Cidade de São Paulo. Recuperado el 9 de junio de 2016, de Esporte e Sociedade: http://www.uff.br/esportesociedade/pdf/es1708.pdf 
Macías, C. (2012). ¿El clásico bajío? Algunas consideraciones históricas sobre una rivalidad social. En R. Magazine, S. Martínez, y S. Varela, Afición futbolistica y rivalidades en el México contemporáneo: una mirada nacional (pp. 143-152). México: Universidad Iberoamericana.

Magazine, R. (2008). Azul y oro como mi corazón: Masculinidad, juventud y poder en un porra de los Pumas de la UNAM. México: Afínita Editorial.

Marsch, P. (1982). El orden social en las tribunas de los estadios de fútbol británicos. Revista Internacional de Ciencias Sociales, 34(2), 279-288.

Marsh, P., Rosser, E., y Harré, R. (1978). The rules of disorder. London: Routledge and Kegan Paul.

Martínez, N., y De la Barca, N. (2009). Barra perra brava: ;Yo le voy al Toluca, Aunque gane! Identidady usos de la comunicación. Recuperado el 12 de febrero de 2020, de Razón y Palabra: http:// www.razonypalabra.org.mx/BARRA\%20 PERRA \% 20BRAVA \%20\%20YO\% 20 LE\%20VOY\%20AL\%20TOLUCA\%20 $\% 20$ AUNQUE\%20GANE\%20IDENTIDAD $\% 20$ Y $\% 20$ USOS\% $20 \mathrm{DE} \% 20$ LA\%20COMUNICACION.pdf

Mateus, G., y Mahecha, V. (2002). Hacia una interpretación etnográfica de una barra de fútbol. Folios, (16), 36-47.

Mendoza, A. (2013). El graffiti y la consolidación de la identidad, y el imaginario del territorio, de los jóvenes de la barra brava Rebelión Auriverde Norte. En Y. Pedraza, y O. Pulido, Memorias Congreso de Investigación y Pedagogia (pp. 2359-2368). Tunja: Universidad Pedagógica y Tecnológica de Colombia.

Miranda, L., Urrego, I., y Vera, D. (2015). Barra brava, cultura, violencia y sociedad: el mundo barrista como representación. Prospectiva. Revista de Trabajo Social e Intervención, (20), 163-191.
Morales, A. (2012). Jaula, barrios y territorios en la porra La Komún de Santos Laguna. En R. Magazine, S. Martínez, y S. Varela, Afición futbolistica y rivalidades en el México contemporáneo: una mirada nacional (pp. 355-373). México: Universidad Iberoamericana.

Morales, G., y Morales, J. (2011). 'Guerrearla'. Algunas caracteristicas de la nueva generación de hinchas del fútbol espectáculo. Una mirada a través del tiempo. Recuperado el 12 de febrero de 2020, de Lecturas: Educación Física y Deportes: http://www.efdeportes.com/efd158/caracteristicas-de-hinchas-del-futbol-espectaculo.htm

Moreira, V. (2009). Aguante, generosidad y política en una hinchada de fútbol argentina. Avá. Revista de Antropología, (12), 79-94.

Oliveto, J. (2000). El vivir "en aguante". Pasión $y$ Goce en el hincha. Recuperado el 12 de febrero de 2020, de Lecturas: Educación Físisca y Deportes: http://www.efdeportes. com/efd27/aguante.htm

Orellana, J. (2012). Los Pumas de la UNAM y sus rivalidades. En R. Magazine, S. Martínez, y S. Varela, Afición futbolistica y rivalidades en el México contemporáneo: una mirada nacional (pp. 61-85). México, D.F.: Universidad Iberoamericana.

Palhares, M., y Schwartz, G. (2015). Não é só a torcida organizada: o que os torcedores organizados têm a dizer sobre a violência no futebol? São Paulo: Universidad Estatal Paulista.

Palhares, M., Cabrera, N., y Schwartz, G. (2014). Apuntes para un estudio comparativo entre torcidas organizadas e hinchadas. Movimento, 20(Número especial), 163-176.

Panfichi, A. (1999). Representación y violencia en el fútbol peruano: barras bravas. Contratexto, (12), 151-161.

Parada, F. (2013). Barras bravas tensiones y convergencias desde una perspectiva híbrida. Revista de Ciencias Sociales, (31), 61-85. 
Pardey, H., Galeano, J., y Blanco, A. (2001). La ciudad de los fanáticos. Aproximación al fenómeno de las barras de fútbol locales Barón Rojo Sur y Frente Radical Verdiblanco entre los años 1999-2001. Cali: Universidad del Valle.

Pimenta, C. (2000). Violência entre torcidas organizadas de futebol. São Paulo em perspectiva, 14(2), 122-128.

Popplewell, O. (1985). Committee of Inquiry Into Crowd Safety and Control at Sports Grounds, Interim Report. London: HMSO.

Recasens, A. (2008). Evolución del fenómeno "barras bravas" en el fútbol. Ponencia presentada en el Primer Encuentro Nacional para la Seguridad y la Convivencia en el Fútbol. Medellín: 6 y 7 de Octubre.

Rodelo, J., y Armienta, W. (2012). El Escuadrón Aurinegro: identidad y representaciones en una barra del equipo de fútbol Dorados de Sinaloa. En R. Magazine, S. Martínez, y S. Varela, Afición futbolística y rivalidades en el México contemporáneo: una mirada nacional (pp. 333-354). México: Universidad Iberoamericana.

Rodríguez, Á. (2003). Los jóvenes Ultras del fútbol Andaluz. Anduli: Revista Andaluza de Ciencias Sociales, (2), 107-124.

Rodríguez, O. (2007). Rituales en La Ultra Morada: la máscara de la pertenencia. Revista Centroamericana de Ciencias Sociales, IV(1), 209-252.

Romero, A. (1997). Apuntes sobre la violencia en el fútbol argentino. Recuperado el 12 de febrero de 2020, de Lecturas: Educación Física y Deportes.: http://www.efdeportes.com/ efd8/amilc81.htm

Roversi, A. (1998). Fútbol, afición y violencia: el gamberrismo futbolístico en Italia. Investigaciones en Ciencias del Deporte, (20), 45-105.

Salcedo, M., y Rivera, Ó. (2007). Emoción, control e identidad: las barras de fútbol en Bogotá. Bogotá: Instituto Colombiano de Antropología e Historia.
Santos, A. (2013). Torcidas Organizadas e Sociabilidade Juvenil no Nordeste. Brasilia: Ministério do Esporte.

Santos, T. (2003). O lado 'hard' da cultura 'cool': as torcidas e a violência no futebol. En P. Alabarces, Futbologias. Fútbol, identidad y violencia en América Latina. (pp. 75-84). Buenos Aires: Consejo Latinoamericano de Ciencias Sociales.

Scharagrodsky, P. (2002). Los graffitis y los cánticos futboleros platenses: o acerca del proceso de configuración de diversas masculinidades. Revista Brasileira de Ciências do Esporte, 24(1), 179-197.

Signorelli, A. (1999). La hinchada y la ciudad virtual. En A. Signorelli, Antroplogia urbana (pp. 189-205). Barcelona: Anthropos Editorial.

Silva, N. (2010). Entre el juego y violencia. Un estudio de caso sobre la agresión entre los jóvenes de las "barras bravas" de Bogotá. Ponencia presentada en el VI Congreso del Consejo Europeo de investigaciones sociales de América Latina. Toulouse: 30 de junio y 1, 2, 3 de julio.

Sodo, J. (2013). Los significados de lo popular en un grupo de hinchas del fútbol argentino. En J. Branz, J. Garriga, y V. Moreira, Deporte y ciencias sociales: Claves para pensar las sociedades contemporáneas (pp. 233-264). La Plata: Editorial de la Universidad de la Plata.

Spaaij, R. (2008). Simpatías y emociones de las barras bravas en el fútbol. En C. Kaplan, La civilización en cuestión. Escritos inspirados en la obra de Norbert Elias (pp. 117-132). Buenos Aires: Miño y Dávila.

Taylor, I. (1971). Football mad: A speculative sociology of football hooliganism. En E. Dunning, The Sociology of Sport: A Selection of Readings (pp. 352-377). London: Frank Cass.

Teixeira, R. (2006). Torcidasjovens cariocas: simbolos e ritualizacao. Recuperado el 9 de junio de 2016, de Esporte e Sociedade: http://www. uff.br/esportesociedade/pdf/es202.pdf 
Toledo, L. (1994). Transgressão e violência entre torcedores de futebol. Revista USP, (22), 93-101.

Torres, C. (2012). Si no se vive, no se sabe lo grande que es. Metodología aplicada a un estudio de barras bravas. En M. Jimeno, S. Murillo, y M. Martínez, Etnografias contemporáneas. Trabajo de campo (pp. 277-308). Bogotá: Universidad Nacional de Colombia. Varela, S. (2012). ¿El club de la polémica o los hijos de Televisa? La identidad americanista a discusión. En R. Magazine, S. Martínez, y S. Varela, Afición futbolística y rivalidades en el México contemporáneo: una mirada nacional (pp. 43-60). México: Universidad Iberoamericana.
Varela, S. (2018). Aguante y violencia en el mundo de las barras futboleras mexicanas. Reflexiones metodológicas y éticas sobre el caso del Ritual del Kaos. Acta Sociológica, (75), 113-134.

Zambaglione, D. (2011). 'El aguante del cuerpo'. Construcción de identidad de los hinchas en un club de fútbol argentino. La Plata: Engranajes de la Cultura.

Zepeda, D. (2012). Necaxa y Aguascalientes, breve historia de un desencuentro. En R. Magazine, S. Martínez, y S. Varela, Afición futbolistica y rivalidades en el México contemporáneo: una mirada nacional (pp. 217-246). México: Universidad Iberoamericana.

\section{Datos de Filiación}

John Alexander Castro Lozano. Candidato a doctor en Estudios Sociales en la Universidad Distrital Francisco José de Caldas, Magíster en Estudios Sociales de la Universidad Pedagógica Nacional y Sociólogo de la Universidad Nacional de Colombia. Además, es profesor — desde 2015 hasta el presenteen el programa de Licenciatura en Ciencias Sociales de la Universidad Antonio Narińo (sede Bogotá) y es profesor ocasional — desde 2016 hasta el presente- en el Departamento de Ciencias Sociales de la Universidad Pedagógica Nacional. También, pertenece al grupo de investigación "Vivencias" de la Universidad Distrital Francisco José de Caldas y "Conciencia" de la Universidad Antonio Nariño. Sus áreas de interés son las teorías sociológicas clásicas y contemporáneas, los estudios sociales del deporte y la historia del conflicto interno en Colombia. 